\title{
Sustainability Awareness through STEAM+
}

\author{
Josef Timmerberg, Jade University of Applied Sciences, Wilhelmshaven, Germany, jt@jade-hs.de \\ Hans-Petter Halvorsen, Håkon Viumdal, Saba Mylvaganam, Faculty of Technology, Natural Sciences \\ and Maritime Sciences, Department of Electrical Engineering, Information Technology and \\ Cybernetics, University of South-Eastern Norway, hans.p.halvorsen@usn.no; \\ hakon.viumdal@usn.no; saba.mylvaganam@usn.no
}

\begin{abstract}
Innovative technology enterprises have been working closely with OECD countries to address issues related to sustainability. There are many acronyms associated with STEM, e.g. STEM+, incorporating the humanities, community needs, and global concerns indicated by the seventeen Sustainable Development Goals (SDG) of the UN. UN Department of Economic and Social Affairs (UNDESA) supports capacity-building for the SDGs and their related thematic issues, including water, energy, climate, oceans, urbanization, transport, science and technology. We prefer to use STEAM+ based on our earlier work, indicating the inclusion of Arts in the curricula to attract female students and interdisciplinarity. Following Briggs' constructive alignment paradigm with focus on learning objectives, activities, and assessments (LO-A-A) in a STEAM+ curricula, sustainability can be included with critical reflective thinking addressing air pollution, microplastics in the ocean, renewable energy, food wastage, circular economy, poverty etc. The paradigm "Student in Centre and Front (CSF)" discussed in our earlier study promotes the idea of the student as a responsible member in the society giving due attention to pressing socioeconomic issues such as the SDGs. In this paper, means of extending the responsibility of the students in developing awareness of issues related to SDGs through curricula and projects are presented. The focus of this paper is on addressing STEAM+ tuned for awakening interest in SDGs, with some examples from courses held in our universities. Examples are taken from learning activities involving group of students as part of selected courses and projects/problembased learning (PPBL) with reflective practice.
\end{abstract}

\section{UN'S AGENDA 2030 AND ITS IMPACT}

During the weekend of September 25 - 27, 2015, at the United Nations Headquarters in New York City, thousands of delegates from member states of the UN, UN diplomats, representatives of Nongovernmental Organizations (NGO), heads of state and the Pope, attended a conference and agreed on a new fifteen-year plan entitled "Transforming Our World: the 2030 Agenda for Sustainable Development" with 17 Sustainable Development Goals (SDG), which were hailed by many and scorned by some during the following years up to the present time. The SDGs as presented by the UN can be found in [1,2]. A frequently used graphical representation of these SDGs is reproduced from [3] in Figure 1. The UN enlists 169 targets, 5337 actions, 1089 events and 1227 publications associated with SDGs in [1]. With such importance given to these SDGs by the UN and supporting nations and NGOs, it is obvious that many educational organisations, major industrial actors, R\&D organisations will address these SDGs and strive for measures for attaining them.

\subsection{Predecessors to agenda 2030}

Agenda 2021 was under focus in the first decade of this century and new ideas were discussed addressing the evolving challenges of the years following resulting in the Agenda 2030. As with all visionary goals of many organisations, Agenda 21 morphed into 2030, with the goal of "living well and within the planet's resources" for all people on the planet. In the UN circles, an agenda for 2050, probably with the name Agenda 2050 is already under discussion.

It is interesting to note that the current prime minister of Norway, Erna Solberg, gave a speech in Sri Lanka during the visit of delegates from Norway in August 2016, focusing on the SDGs particularly addressing the then burning issues of Sri Lanka. In the Norwegian perspective, it is relevant to cite an important statement during the speech given by Erna Solberg on $12^{\text {th }}$ August 2016, almost a year after the UN meeting on SDGs in New York, [4]: "As co-chair of UN Secretary-General Ban Ki-moon's 
Sustainable Development Goals Advocacy Group, I am pleased that the development priorities of Sri Lanka are in line with the SDGs. As Prime Minister of Norway, I am also pleased that these priorities shape our bilateral development cooperation."

Prior to the announcement of SDGs, there have been efforts by Gro Harlem Brundtland and Schumacher in addressing sustainability and development. Cocklin addresses the methodological problems associated with the evaluation of sustainability, which is still an issue for discussion, [5]. Schumacher discusses in [6] the statement attributed to Mahatma Gandhi, "Earth provides enough to provide for every man's need, but not enough for every man's greed" and coined the jargon "Small is beautiful", which influenced the educational, societal, and industrial trends in the 1970s, particularly after the energy crisis of 1973. "Sustainability" has become the buzzword in the 1980s, although sustainability has been addressed in relation to fisheries already in the 1970s and used as the objective of environment management and development planning. The most influential initiative with continuing support has been the work of the World Commission on Environment and Development (WCED) by the UN under the chairmanship of Gro Harlem Brundtland. The report of WCED "Our Common Future", [7], promoted the idea of "sustainability" extending its scope and reach in all aspects of human activities as enlisted in the SDGs of Figure 1 (a). With the launch of 17 SDGs by the UN, the sustainability (in nominative as well as adjective form) appears in almost all contexts of our current societies. A "Bing" web-search of "sustainability" delivers 253 million hits, on $7^{\text {th }}$ February 2021!

\subsection{UN's Agenda 2030 - Main Items}

The 17 SDGs given in Figure 1 addresses Schumacher's vision around "Small is beautiful", which are centred around four main topics: "The Modern World", "Resources", "The Third World", and "Organization and Ownership", with some of these terminologies still being used in the current discussions on "sustainability". According to the WCED, "sustainable development is development that meets the needs of the present without compromising the ability of future generations to meet their own needs", which is still a useful definition with more elaborations as given in the 17 SDGs of Table 1 and Figure 1 (a). From an educational perspective at tertiary level, the SDGs will come into play in most of the curricula, when these issues are taken up with clear focus on their interplay as described in [8]: "In general, sustainability is understood as a form of intergenerational ethics in which the environmental and economic actions taken by present persons do not diminish the opportunities of future persons to enjoy similar levels of wealth, utility, or welfare."

Any engineering curriculum with an interdisciplinary approach will be able to address at least some of the 17 SDGs. A study of the 17 SDGs shows that SDG 4 is dedicated to education per se. Target 4.3 of SDG 4 is addressing higher education with a clear Agenda 2030 goal, [9]: "By 2030, ensure equal access for all women and men to affordable and quality technical, vocational and tertiary education, including university." In addition, according to UNESCO, [9], higher education must address issues related to poverty (SDG1); health and well-being (SDG3); gender equality (SDG5) governance; decent work and economic growth (SDG8); responsible consumption and production (SDG12); climate change (SDG13); and peace, justice and strong institutions (SDG16), among the 17 SDGs.

UNESCO points out that the "The roadmap for SDG4, the Education 2030 Framework for Action (FFA), has two central policy pillars which focus on monitoring and improving learning outcomes and those who are excluded.", [9]. Monitoring and improving learning outcomes have been discussed in the context of Biggs' constructive alignment. Constructive alignment is based on an alignment-based tuning of learning outcomes, activities, and assessment, as promulgated by Biggs. Constructive alignment is mainly based on curricula assessing students' performance and is defined by Biggs as the process involving "coherence between assessment, teaching strategies and intended learning outcomes in an educational programme". The strategy of UNESCO as promulgated in [9] can be used for achieving major targets aimed by the SDGs: "The FFA calls for progress regarding existing international agreements in favour of higher education and recognizes that a well-established and well-regulated tertiary education system can improve access, equity, quality and relevance. It can also reduce the dissonance between what is taught and what needs to be learned to ensure sustainable development and take advantage of technology, open educational resources and distance education." Constructive alignment can indeed be used to reduce the dissonance mentioned by UNESCO using the leverage of technology, open educational resources and distance education, as has been proven by the scenario in 
all educational sectors during the Covid-19 pandemic over the last 13 months, which have given rise to innovative educational platforms using cloud-services and online courses in the form of on-demand multimedia contents and real-time webinars. UNESCO operates at "regional and national levels in close cooperation with donors, Member States, and stakeholders, to address quality enhancement, internationalization and digital education", [9], which have undergone tremendous developments due to the necessity imposed by the Covid-19 pandemic.

\section{ACRONYMS - STEM, STEM+, STEAM AND STEAM+}

The low percentage of females in STEM (Science, Technology, Engineering and Mathematics) related studies is still a problem for many educational institutions. In an IEEE study, the idea of adding an A (for Arts) in STEM leading to STEAM (Science, Technology, Engineering, Art and Mathematics) was discussed and its effects were presented in [12]. With gamification as an interesting addendum in many subjects and associated elements of Art in many disciplines, STEAM has shown to improve the number of female students enrolling for the traditional STEM courses, as confirmed by a study performed in 2016, [11]. In the process of including Arts in STEM disciplines leading to STEAM, there has been efforts to incorporate other disciplines in STEM, leading to the acronym STEM+ for STEM (or STEAM) with curricula involving arts, music, environmental awareness etc. STEAM was promoted as a means of achieving focus on imagination, critical and creative thinking with focus on problem/project based learning as shown in Figure 2. With the focus on SDG 4 and SDG 5 and more inclusively all 17 SDGs, STEAM+ is a better acronym to be used in higher educational scenario involving tertiary education.

\subsection{STEAM+ in tertiary education}

As shown schematically in Figure 1(b), many links are possible within the sets of STEAM scenario discussed in [12] and the SDGs defined by UN with clear commonalities between STEAM and SDG 4 and SDG 5. With many tertiary educations in STEAM+ focusing on entrepreneurial ventures as part of the curricula, the integration of SDGs in the curricular activities can enhance STEAM+ strategy for tertiary education.

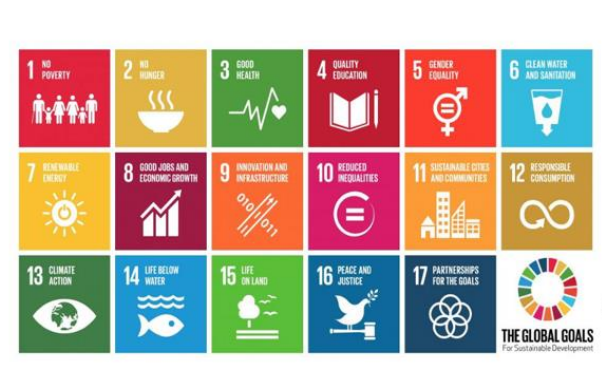

(a)

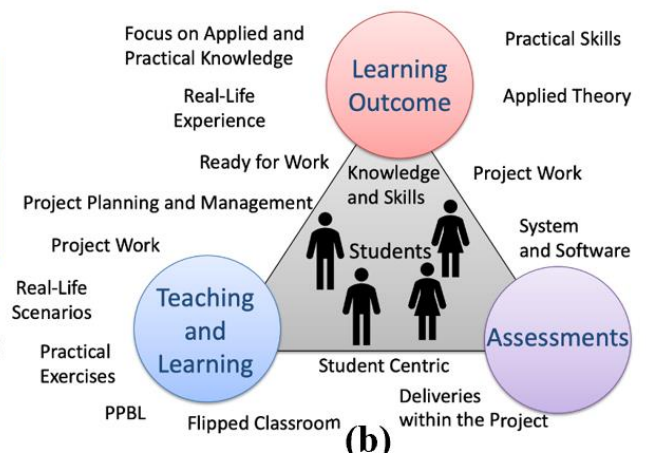

(b)

Figure 1. (a) Visions of Sustainable Development Goals as presented by UN, [3]. Note SDG 4 with its sub-goals addresses specifically higher education including tertiary education. SDG5 obviously addresses promoting gender equality, thus addressing issues relevant to STEAM. (b) STEAM+ including SDGs - Concerted action by the Industry, academia, government, and professional societies. Integration of economic, technological, social, and economic actions with the preservation of the environment, based on [1] and [12]. PPBL-Project and Problem Based Learning. Reflective practice for connecting theory and practice using PBBL is an effective way of addressing these diverse issues in all courses.

In the academia, there is an increased focus on SDGs, as can be seen in the activities of many universities, e.g. in Germany, Norway, and UK, [13, 14, 15, 16, 17]. In [16], Nabarro, the Chair of Global Health of Imperial College London states, "These seventeen goals are universal; they apply to the whole world, and they're densely interconnected."

\section{AGENDA 2030 IN ENTERPRISES}

Many enterprises and government organisations have included the SDGs in their visions for progress of their activities. SINTEF has also listed the status quo of the commitment of the organisation directly addressing the 17 SDGs. SINTEF has visions of using SDGs for orienting the portfolio and creating new research projects and start-ups, [17]. It is interesting to note that SINTEF has an overview, Figure 
2, of their investments sorted into the set of the 17 SDGs promulgated by the UN in 2016! Similarly, in Germany, sustainability is a key issue taken by academic and governmental organisation, [19]. Many companies select a subset of the 17 SDGs to decide on the priorities based on strategic planning and on the potential impact of their decisions.

\section{INCORPORATION OF AGENDA 2030 IN STEAM+ CURRICULA}

In this section, we enlist selected activities directly addressing selected SDGs within the STEAM+ paradigm in tertiary education in curricula, research and doctoral and postdoctoral studies.

Some examples of concrete projects within the STEAM+ paradigm discussed in this paper employing PPBL are the following: 1. Development of new measurement methods for the detection of microplastics in water as well as monitoring and reporting mechanism. 2. Establishment of a new website, a portal for environment and health in selected regions in Europe. The portal will make it easier for the population to make good health choices. 3. Infrastructures related to real-time air pollution monitoring using sensors and IoT solutions for process industries. 4. Measurement and Monitoring of Solar Panels in combination with Weather Data from Weather Station. 5. Another engineering task contributing to the UNs SDGs is the usage of floating solar panels. 6. Environmental Public Health Information Management System, Information Management System for Environmental and Public Health Information 7. Renewable Energy from wind energy farms and hydroelectric power stations. 8. Alleviating food wastage with IoT solutions 9. Localisation of submarine cables for protection of the marine fauna and flora to avoid heating effects of the marine environment. 10. Wind energy and gridnetwork - Preventing and predicting outages.

Most of these activities were carried out within the paradigm of STEAM+ involving academic, R\&D and industrial partners within EU and involving international students from industrialised and developing nations, thus addressing another goal of UNs SDGs. Integration of the UN's SDGs and the student(s) in centre paradigm using constructive alignment for tuning learning outcomes using PPBL as represented in Figure 1(a) \& (b) will help the STEAM+ strategy to be implemented successfully at all educational levels, covering from primary via secondary to tertiary levels. Some of these activities are discussed from the perspectives of policy makers in [20,21]. In a freshly published report on the future of process industries in Norway, the industrial cluster "Process 21 " plans to achieve zero emission process industries by 2015 and presents the emission reduction of $\mathrm{CO} 2$ shown in Figure 3. "Prosess21 was initiated by the Ministry of Trade, Industry and Fisheries in April 2018 with the main task of providing strategic advice and recommendations on how Norway can best achieve its goal of sustainable growth whilst minimizing emissions", cited from [22], shows the efforts from another industrial cluster in setting clearly defined SDG with respect to zero emission of climate gases. Germany had the share of clean energy boosted to $46 \%$ in 2020 reducing total green house emissions by $42 \%$ from the 1990 level surpassing the set target by $2 \%$, [23].

\section{CONCLUSIONS}

The Norwegian Prime Minister Erna Solberg formulates the SDGs in an easily fathomable form during her talk in Sri Lanka, [4]: "the Sustainable Development Goals are not just a means of fixing what is broken in our world; they will put the world on a new, sustainable path". Industry, academia, government, and professional societies need to put a concerted effort to promote the dissemination of the potentials of following a STEAM+ higher education with a continuous focus on constructive alignment of learning outcomes incorporating SDG 4 and SDG 5, preferably all the 17 SDGs promulgated by the UN in 2015. The activities in academia, industries and organisations in the past five years confirm the dedication and the concerted action in many countries of the world. STEAM+ as envisioned in Figure 1 (a) \& (b) will help the students of both genders in tertiary education to enhance their awareness of SDGs. The UN has declared $11^{\text {th }}$ of February as the International Day of Women and Girls in Science thus including the whole spectrum of education through vocational training via tertiary education into the frontiers of STEAM+ activities for women and girls, [24], avoiding the phenomenon of "Leaky Pipeline Effect" depicting the dropouts of many girls and women during their education and career due to pregnancies, childbirths and family care making their $100 \%$ dedication to education or work not always possible. With the outbreak of Covid-19, the practice involving the prolific usage of digital platforms for teaching, discussing, and testing with continuous availability of resources such as 
webinar contents and demonstrations will enable women and girls dropping from courses due to "Leaky Pipeline Effects" to follow their studies to completion.

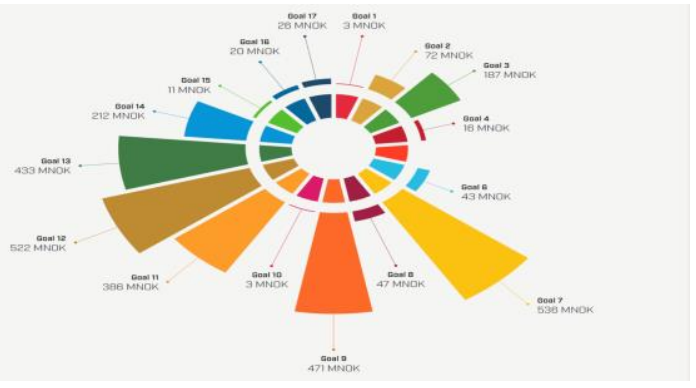

Figure 2. Turnover per SDG of the Research Organisation SINTEF in 2019, [18, 19]. A very dedicated approach in achieving UN's SDGs. Curricular development should also have these SDGs in the portfolio at all levels addressing such issues as discussed in [22].

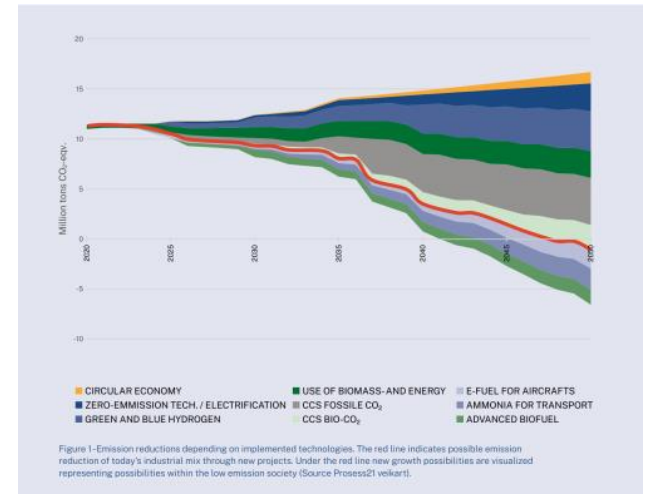

Figure 3. Emission reduction based on new technologies - vision towards 2050 - going beyond 2030, dependent on STEAM+, [22], with relevant topics for reflective practice in connecting theory and practice.

REFERENCES (all cited websites retrieved on February 7, 2021)

[1] https://sdgs.un.org/goals

[2] "Transforming our world: the 2030 Agenda for Sustainable Development"

[3] Communications materials - United Nations Sustainable Development

[4] Norway PM praises Lankan development policies | Daily FT

[5] Cocklin, C. (1989). Methodological Problems in Evaluating Sustainability. Environmental Conservation, 16(4), 343-351. Retrieved February 7, 2021, from http://www.jstor.org/stable/44521205

[6] Schumacher, E. F. (1999). Small is Beautiful: Economics as if People Mattered: 25 Years Later...With Commentaries. Hartley \& Marks Publishers ISBN 0-88179-169-5

[7] Report of the World Commission on Environment and Development : (un.org)

[8] sustainability | Description, Theories, \& Practices | Britannica

[9] Higher education and the Sustainable Development Goals (unesco.org)

[10] Halvorsen, H-P., Timmerberg, J., Mylvaganam, S. (2019). Constructive Alignment with Student in Centre and Front Experience from Case-projects and Intensive Summer Courses, MNT-Conference 2019, Norway.

[11] Perry, T.S., 2016, "Want Girls Attracted to Tech? Put an "A" for "Art" in STEM, Two Bit Circus continues its push to move the conversation from STEM to STEAM", 14.Dec. 2016.

[12] Halvorsen, H-P., Rasma, T. Timmerberg, J. \& Thiriet, J-M., Mylvaganam, S. (2019). STEAM for STEM Include "Art" in STEM. 1-7. 10.1109/EAEEIE46886.2019.9000460.

[13] STEM | (stonybrook.edu)

[14] NTNU Sustainability - NTNU

[15] Sustainability | About | Imperial College London

[16] The 2030 Agenda for Sustainable Development: What it means for all of us | Imperial News | Imperial College London

[17] INEV - Institut für nachhaltige Energieversorgung- Jade Hochschule (jade-hs.de)

[18] Sustainability in SINTEF - How SINTEF research contributes to the UN's sustainability goals

[19] SINTEF, (2020). Sustainability Report SINTEF - Technology for a better Society.

[20] Nachhaltigkeit in der beruflichen Bildung - BMBF

[21] Bückmann, W., (2015). Die Vision der UNO für die Zukunft der Welt: die 2030-Agenda für nachhaltige Entwicklung, FAGUS Schriften, Band 17, Universitätsverlag der TU Berlin.

[22] Process 21, Hovedrapport, (2021).

[23] Is Germany Making Too Much Renewable Energy? (foreignpolicy.com)

[24] International Day of Women and Girls in Science / United Nations, 